\title{
Membrane Stabilitiy and Removal of Cobalt from Waste Solution Using Liquid Emulsion Membrane
}

\author{
Y.T. Mohamed ${ }^{1, *}$, L.M.S. Hussin ${ }^{1}$, H.M.H. Gad ${ }^{1}$, A.A.M. Daifullah ${ }^{1}$ and S.A. Abo-El-Enein ${ }^{2}$ \\ ${ }^{1}$ Hot Laboratories and Waste Management Center-Egyptian Atomic Energy, Egypt \\ ${ }^{2}$ Chemistry Department, Faculty of Science, Ain-Shams University, Egypt
}

\begin{abstract}
A Liquid Emulsion Mmenrane (LEM) containing Cyanex 301 as a carrier and Span 80 as a surfactant was used for the extraction of Co-(II) from nitric acid solution. Various diluents were tested and cyclohexane was found the most effective diluent in the cobalt extraction. The effect of different factors affecting the permeation of cobalt through LEM (e.g pH of the extrenal phase, type and concentration of stripping internal phase, the equilibrium time, and Cyanex 301 conentration) were investigated. The effects of surfactant types and cocentrations on the stbility of LEM were also studied. It was found that the optimum conditions for cobalt extraction using $8 \%$ Cyanex 301 were as follows; $3 \mathrm{M} \mathrm{HCl}$ as an internal phase, $4 \%$ span 80 as a surfactant and by using the best conditions $10 \mathrm{ml}$ of prepared LEM can extract about $96.86 \%$ of $1 \mathrm{gm} / \mathrm{l}$ of cobalt in Nitric acid solution after $5 \mathrm{~min}$. in the reactor tank.
\end{abstract}

Keywords: Liquid Emulsion membrane, Cobalt Extraction, membrane Stability.

\section{INTRODUCTION}

Cobalt has many industrial and nuclear applications, where it is used to produce some alloys with iron, nickel, chromium, and manganese [1]. It is also used in the manufacture of dyes for paints and ceramics, as a catalyst, in medicine and nuclear industry, and as an additive for fertilizers. Cobalt releases to the environment by leaching from acid coal mine drainage and emissions to the atmosphere from coal burning. Several methods are used to remove cobalt from industrial and radioactive waste solution such as chemical precipitation, ion exchange, adsorption, reverse osmosis, biosorption ...etc. Normal available technologies are not a solution because they are expensive and not too effective and usually the cobalt concentration in these waste solutions is low, making its recovery uneconomical. Compared to conventional processes, liquid emulsion membrane (LEM) process has certainly some attractive features. e.g., simple operation, high efficiency, both extraction and stripping steps were combined in one stage, which led to simultaneous purification and concentration of the solute [2]. LEM process has the ability to selectively remove and concentrate the low metal contents in aqueous solution, in a continuous and fast process, that present large interfacial area, needing only a very small volume of organic solvent. LEM technique has been used for separation of phenol [3] substituted phenol [4] nitro phenol compound [5] and toluene/nheptane from industrial effluent [6], extraction of metals

*Address correspondence to this author at the Hot Laboratories and Waste Management Center-Egyptian Atomic Energy, Egypt; Tel: +201004613570; Fax: +202-44620772; E-mail: ytselim@yahoo.com
[7-15] and amino acid [16, 17]. In medical field, this technique has utilized for separation of toxic compound in blood [18], and extraction of cephalexin [19]. A cation carrier was needed in metal extraction process by LEM. The cation carriers that usually used are salicylaldoxim [20], benzoylacetone [21], diisostearylphosphoric acid [22], p-tert-butylcalixaren [23], trioctylmethyl ammonium chloride [24], tri- $n$ octylamin (TOA) [25], di-2-ethylhexyl phosphoric acid (HDEHP) [26-28] $\mathrm{N}$-alkylcaprolactam [29], tertieramine [30], ketoconazol [31], dinonylnaphthalensulphonate [32] Although these carrier were deeply used in metal extraction by LEM technique, however they were used in high concentration up to $20 \%$ [33]. Therefore it is less efficient and uneconomical. The inestigators [3437] studied the separation of cobalt, nickel and copper by solvent extraction using di-(2-ethyheyl) phosphonic acid (PC88A) as liquid cation exchangers and using EDTA as a masking agent in the separation of cobalt and nickel by LEM and others using CYANEX 923 in extractive spectrometric determination of cobalt (II) in synthetic and pharmaceutical samples. Reddy et al. [38] showed that CYANEX 923 can be used in recovery of cobalt and nickel from spent catalysts. Investigated the applicability of LEM process for removal of cobalt and studied the extraction of cobalt from simulated industrial leaching liquor by liquid surfactant membranes using CYANEX 302 as a carrier and good results for cobalt-nickel separation by the supported liquid membrane technique was obtained. Some researchers used 2-ethylhexyl phosphonic acid mono 2-ethylhexyl ester (PC-88A) in the recovery of Co (II) ions from a dilute sulphate solution containing nickel (II) ions, and the results proved that SPAN 80 membranes are hydrolyzed readily in a moderate acidic sulphate 
solution to from viscous gel and excess carrier $\left[(\mathrm{HR})_{2}\right]$ affects the stability of emulsion and thus the separation factor.

In this study, the optimum conditions for Co (II) extraction from nitrate medium by LEM were examined. In this concern, the effects of various parameters on cobalt (II) extraction were investigated.

\section{EXPERIMENTAL}

\subsection{Materials}

Cobalt chloride of analytical reagent grade (ARgrade) was supplied by Sigma. CYANEX 301 is bis (2, 4, 4-trimethylpentyl) dithiophosphinic acid extractant of analytical grade (CYTEC) was used. Several surfactants (AR-grade) from Fluka have been tested e.g. Span 80 (sorbitan monooleate), Arlacel A and Sorbitan Sesquioleate. The diluents used were toluene, benzene and cyclohexane from Merck.

\subsection{Procedure}

The external aqueous phase is obtained by dissolving the cobalt chloride in nitric acid medium. The internal aqueous phase is of analytical grade, obtained from Merck. In this concern, sulfuric acid, hydrochloric acid, phosphoric acid, and nitric acid solutions were the stripping agents tested to optimize. The organic phase was CYANEX 301 in different diluents

\subsubsection{Liquid - Liquid Extraction Investigation}

Liquid-liquid extraction of cobalt was carried out by adding equal volumes $(25 \mathrm{ml})$ of aqueous and organic solutions in thermal shaker at $25{ }^{\circ} \mathrm{C}$ for $1 \mathrm{~h}$, the aqueous and organic phases have been separated using centrifugation.

\subsubsection{Liquid Emulsion Membrane}

All LEM experiments were prepared by mixing $25 \mathrm{ml}$ of the organic extractant in the selected diluent with suitable surfactant. Then $25 \mathrm{ml}$ of the stripping aqueous phase solution was added drop-wise to enhance the stability of LEM. The solution was then emulsified with an ultra-high speed homogenizer. A stirring speed of $7000 \mathrm{rpm}$ was used for 5 minutes to form the emulsion. The prepared emulsion was then poured into the external aqueous phase containing the cobalt ions. The system was stirred with a magnetic stirrer at $350 \mathrm{rpm}$. Samples were taken at different time intervals from the external aqueous phase for analysis. The concentration of cobalt was determined using the spectrophotometer (Shimadzu model 160A doublebeam UV spectrophotometer) using ammonium thiocyanate method.

The extraction percentage (E, \%) was calculated by the relation:

$E(\%)=\left[\left(C_{0}-C_{t}\right) / C_{0}\right] \times 100$

Where $\mathrm{C}_{0}$ is the initial concentration of metal ions in the feed solution and $\mathrm{C}_{t}$ is the metal ion concentration in the feed solution after time interval, t.

The distribution ratio (D) was calculated as the ratio of the Co (II) concentration in the organic phase to that in the aqueous phase.

$D=\frac{C_{0}-C_{e}}{C_{e}}$

Where $\mathrm{C}_{0}$ is the initial concentration of metal ions in the feed solution and $\mathrm{C}_{\mathrm{e}}$ is the concentration at the equilibrium time.

\section{RESULTS AND DISCUSSION}

\subsection{Liquid -Liquid Extraction Investigation}

\subsubsection{Effect of Diluents Type in the Extraction of Co(II) lons}

The suitability of some diluents for the extraction of cobalt (II) by the proposed method was tested. Table 1 showed that cyclohexane gives the maximum extraction (88\%) as a diluent.

Table 1: Effect of Diluent Type on the Percent of Cobalt Extraction

\begin{tabular}{|c|c|}
\hline Diluent type & Extraction (\% E) \\
\hline \hline Cyclohexane & 88 \\
Toluene & 69 \\
Benzene & 58.5 \\
\hline
\end{tabular}

\subsubsection{Effect of Nitric Acid Concentration}

The extraction percent of cobalt ions $(100 \mathrm{mg} / \mathrm{l})$ using different nitric acid concentrations from 0.01 to 2.0M was tested. As shown in Figure 1, the extraction of cobalt ions decreases with increasing nitric acid concentration. It was clear that the lowest extraction percent was $\% 10$ at $2 \mathrm{M}$ (the maximum nitric acid concentration). This may be referred to the fact that the cationic exchange being more difficult when the acidity increased [25]. These results indicate that cyanex 301 
is suitable for the extraction of cobalt ions at low nitric acid concentration $\left(10^{-2} \mathrm{M}\right)$.

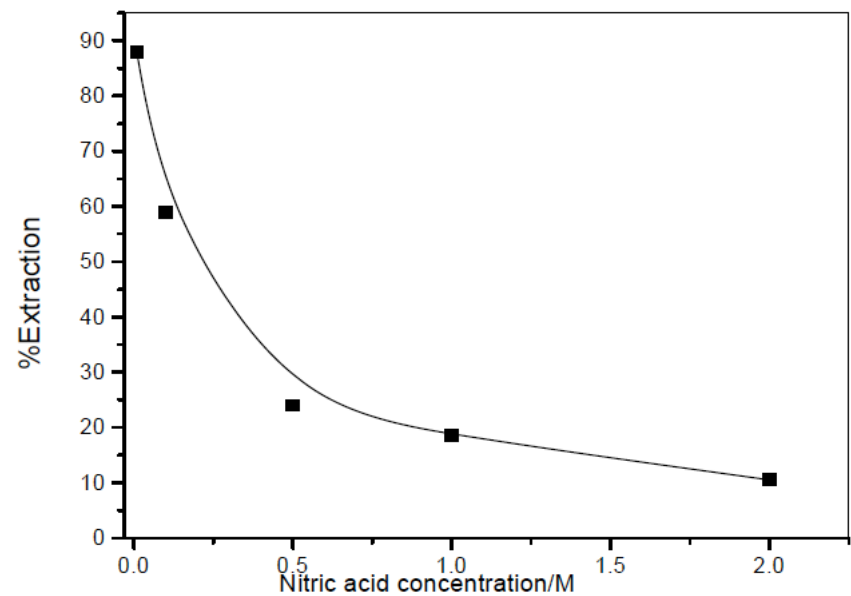

Figure 1: Effect of nitric acid concentration on the percent of extration of cobalt by cyanex in cyclohexane.

\subsubsection{Effect of Type of Stripping Agents}

Stripping of the extracted cobalt species from their organic phases was investigated using different stripping agents. Aqueous solutions of $\mathrm{HCl}, \mathrm{H}_{2} \mathrm{SO}_{4}$, $\mathrm{H}_{3} \mathrm{PO}_{4}, \mathrm{HNO}_{3}$ and $\mathrm{NaOH}$ were tested as stripping agents. The data obtained are given in Table 2. From this table, it is clear that, $\mathrm{HCl}$ is the best stripping agents for cobalt ions from CYANEX 301 as compared to $\mathrm{H}_{2} \mathrm{SO}_{4}, \mathrm{H}_{3} \mathrm{PO}_{4}, \mathrm{HNO}_{3}$ and $\mathrm{NaOH}$.

Table 2: Effect of Different Stripping Agents on the Stripping \% of Cobalt from Cyanex 301 in Cyclohexane

\begin{tabular}{|c|c|}
\hline Stripping agent & Stripping efficiency, \% \\
\hline \hline $\mathrm{HCl}, 3 \mathrm{M}$ & 81 \\
$\mathrm{H}_{2} \mathrm{SO}_{4}, 3 \mathrm{M}$ & 50 \\
$\mathrm{H}_{3} \mathrm{PO}_{4}, 3 \mathrm{M}$ & 50.2 \\
$\mathrm{HNO}_{3}, 3 \mathrm{M}$ & 46 \\
$\mathrm{NaOH}, 0.1 \mathrm{M}$ & 4 \\
\hline
\end{tabular}

\subsubsection{Effect of Stripping Agent Concentration}

The effect of stripping agent concentration on the extracted Co(II) from CYANEX 301/ cyclohexane was studied. Figure 2 showed that the stripping efficiency of Co (II) increases with increasing the concentration of $\mathrm{HCl}$ from 0.01 to $5 \mathrm{M}$. This may be due to the increase of hydrogen ion concentrations in the right hand side of the equilibrium equation (3) which enhance the reversible reaction direction

$\mathrm{M}^{2+}+2 \mathrm{HB} \leftrightarrow \mathrm{MB}_{2}+2 \mathrm{H}^{+}$

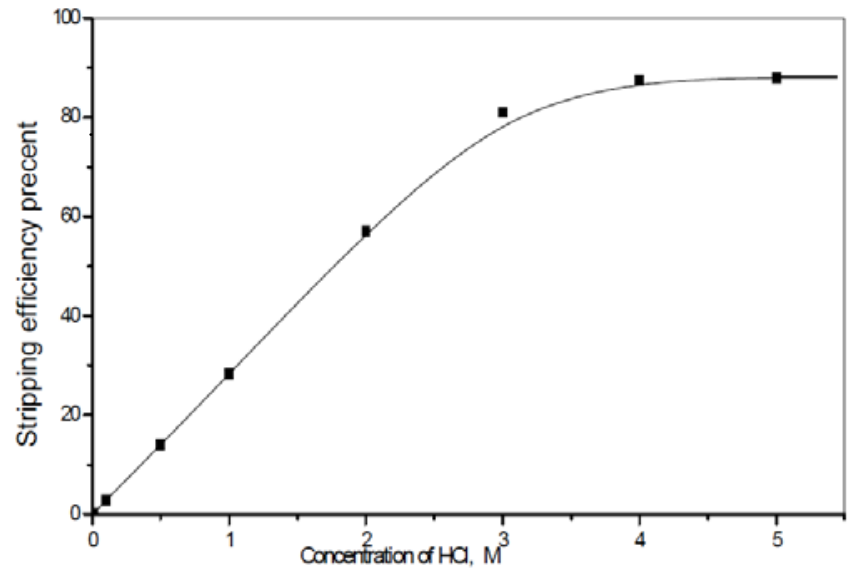

Figure 2: Effect of $\mathrm{HCl}$ concentration on the stripping of Co(II)from CYANEX 301/cyclohexane solution: [Co(II)] $=100$ ppm, CYANEX 301=4\%(v/v), [HNO3] $=0.01 \mathrm{M}$.

\subsubsection{Effect of Shaking Time}

Kinetic investigation was carried out in order to determine the effect of shaking time on the extraction $\%$ of cobalt ions $(100 \mathrm{mg} / \mathrm{L})$ in $10^{-2} \mathrm{M} \mathrm{HNO}_{3}$ by CYANEX 301/ cyclohexane. In this concern, the time ranging from 1 to 20 minutes were tested. The results are depicted in Figure $\mathbf{3}$, it is obvious that the extraction percent of Co ions increases with increasing the shaking time and the maximum extraction \% obtained was $88 \%$ after 15 min.

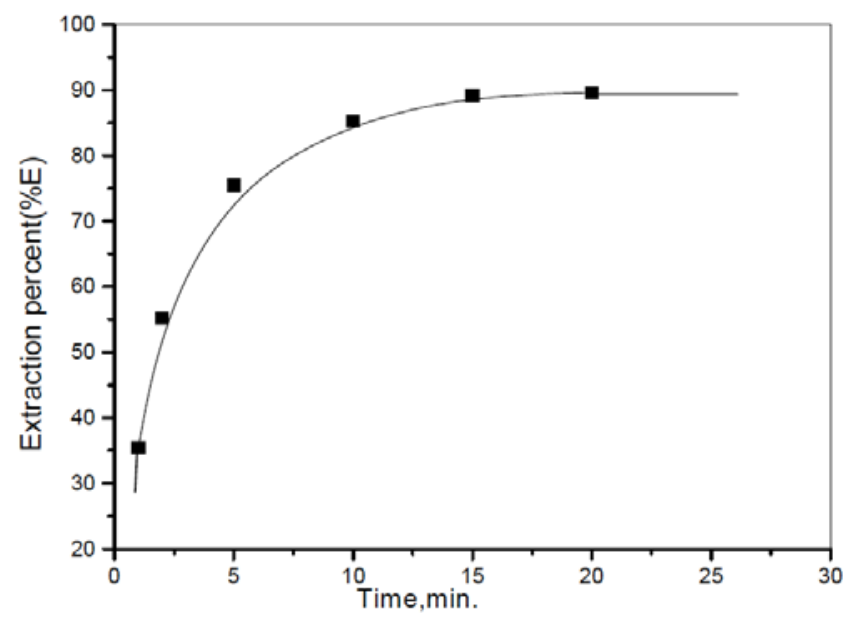

Figure 3: Effect of time on the extraction of cobalt by CYANEX 301 in cyclohexane from $0.01 \mathrm{M}$ nitrate medium: $[\mathrm{Co}(\mathrm{II})]=100 \mathrm{ppm} ;[\mathrm{CYanex} 301]=4 \%(\mathrm{v} / \mathrm{v}) \mathrm{T}=25 \pm 1^{\circ} \mathrm{C}$.

\subsubsection{Effect of Carrier Concentration}

To study the effect of carrier concentration, cobalt (II) ion was extracted from $10^{-2} \mathrm{M} \mathrm{HNO}_{3}$ using various concentrations of CYANEX 301. The CYANEX 301 concentrations were varied from 2-8 \% (V/V). The data presented in Figure 4 as a log-log relation between the distribution ratio of cobalt (II) and CYANEX 
301 concentrations. A straight line with slope $\approx 2$ was obtained.

Accordingly, the following extraction equilibrium is proposed.

$\mathrm{M}^{2+}+2 \mathrm{HB} \rightarrow \mathrm{MB}_{2}+2 \mathrm{H}^{+}$

Since CYANEX 301 is known to extract metal ion species as $\mathrm{MB}_{2}$ and from the slope obtained, Where $\mathbf{M}^{2+}=\mathrm{Co}(\mathrm{II}), \mathbf{H B}$ is the extractant (CYANEX 301).

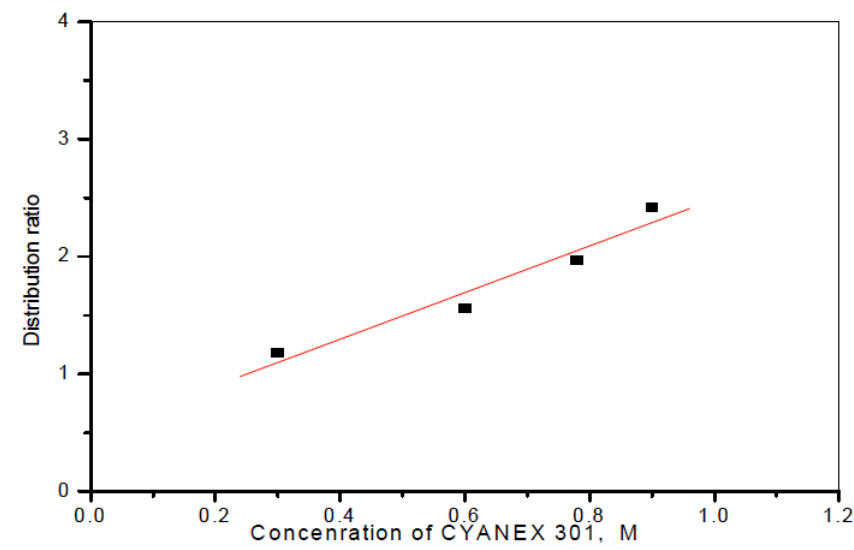

Figure 4: Effect of CYANEX 301 concentration on the distribution ratio of cobalt from $0.01 \mathrm{M}$ nitric acid.

\subsection{Emulsion Stability}

When LEM is dispersed in the external aqueous phase, the emulsion must be sufficiently stable in order to extract the metal ions into the internal aqueous, as the LEM breakdown will result on operation failure and lower the extraction efficiency and loss of the extracted species. The LEM globules are stabilized by adding suitable surfactant and the degree of extracted metal species into the internal aqueous phase is highly affected by the degree of LEM stability. The stability of LEM was investigated by tracing the red dye (acid red 73) which loaded in the internal aqueous phase and detect the leakage in the external aqueous phase. The percentage of leakage (\%) was determined using the following equation (5) (Miesiac et al., 1992).

Leakage $(\%)=\frac{C_{e x t}}{C_{e x t} \max } X 100$

Where: $\mathrm{C}_{\text {ext }}=$ the concentration of red dye leaked from the internal phase to the external phase and $\mathrm{C}_{\text {ext, }}$ $\max =$ the max concentration of red dye in the external phase. The emulsion composition used during the stability studies of membrane under investigation was the following unless otherwise stated, concentration of Cyanex 301 was $6 \%(\mathrm{v} / \mathrm{v})$, different surfactants were used; and the internal aqueous phase was in the range $0.5-5 \mathrm{M} \mathrm{HCl}$, a ratio of membrane / internal phase ratio is 1 , rotating speed of $350 \mathrm{rpm}$, and a red dye (acid red 73) was used as a tracer, and the temperature was $25{ }^{\circ} \mathrm{C}$. The external aqueous phase was $0.01 \mathrm{M}$ nitric acid containing cobalt ions and the membrane /feed ratio was $10: 100 \mathrm{ml}$.

\subsubsection{Effect of Surfactant Type}

Surfactants play very important role in the formation and the stability of liquid emulsion membrane. The effect of surfactant type on the amount of red dye leaked from the internal aqueous phase to the external aqueous phase was studied at constant concentration of $4 \% \mathrm{v} / \mathrm{v}$ using the following surfactants: span80, ArlacelA and sesquioleate. Figure $\mathbf{5}$ showed the leakage percent versus time for the different surfactants under investigation. In this concern, Span 80 has the lowest leakage percent $(\approx 5 \%)$. i.e., it has the highest stability for the LEM globules.

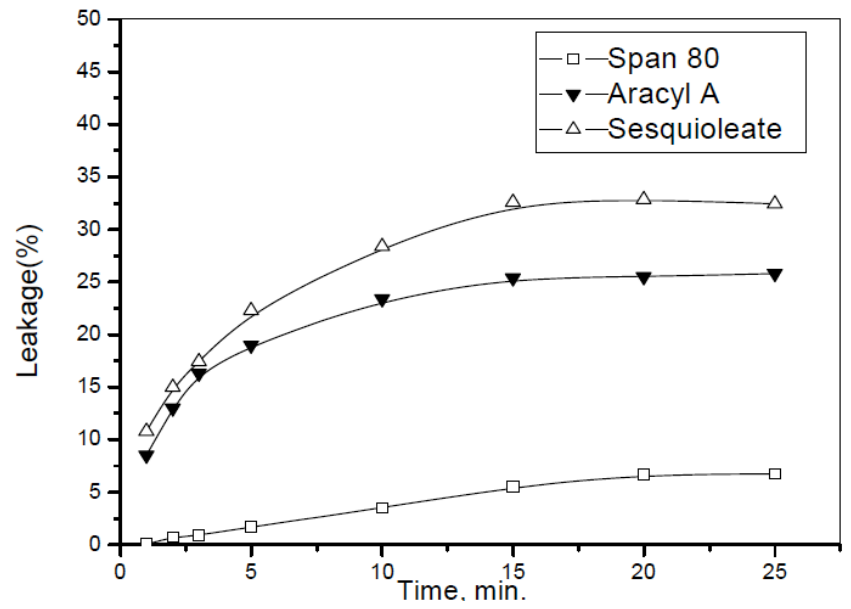

Figure 5: Effect of type of surfactant on the leakage(\%) of LEM in nitric acid medium.

\subsubsection{Effect of Surfactant Concentration}

The effect of surfactant concentration (Span 80) on the prepared LEM was studied. In this concern, three various concentrations of span 80 were tested: $2 ; 4$ $6 \%$. As shown in Figure 6 , the stability of LEM increases with increasing span 80 concentration and there is no big difference in stability between $4 \%$ and $6 \%$, therefore $4 \%$ span 80 concentration was selected as the best concentration avoiding the probability of LEM swelling.

\subsubsection{Effect of Internal Phase Concentration on LEM Stability}

Experiment was conducted under the same conditions as mentioned previously, different 


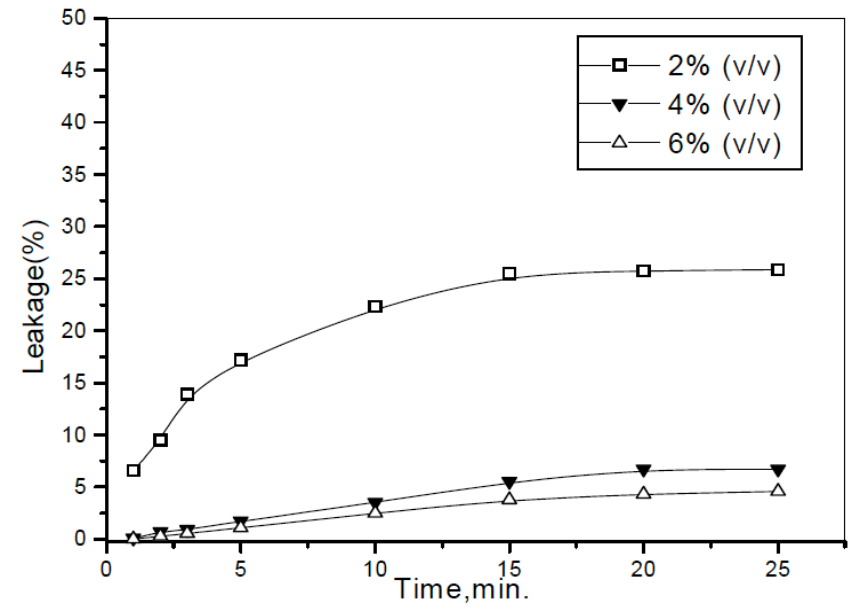

Figure 6: Effect of surfactant concentration on the leakage(\%) of LEM in nitric acid medium.

concentrations hydrochloric acid as internal aqueous phase from 0.5 to $5 \mathrm{M}$ was tested to study the stability of LEM under each concentration. Figure 7 Shows that the stability of LEM decreases with increasing the $\mathrm{HCl}$ concentration. This may be due to the effect of conc. $\mathrm{HCl}$ on the organic oil layer in LEM which responsible for the stability of membrane.

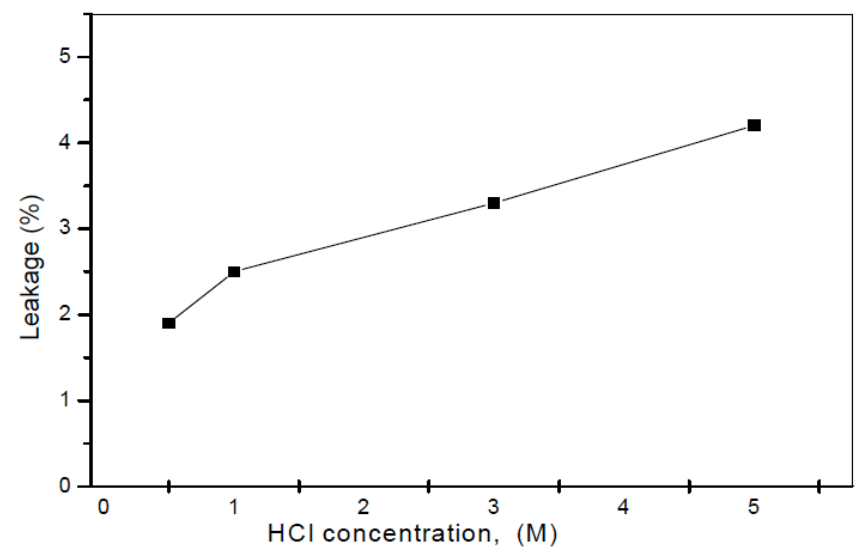

Figure 7: Effect of stripping phase concentration on the stability of emulsion in nitrate medium.

\subsection{Extraction Kinetics of Co (II) by LEM}

To describe the overall permeation kinetics of $\mathrm{Co}(\mathrm{II})$ we used the model reported by Teramoto et al. [39]. In order to predicts a quantitative measure of kinetics of $\mathrm{Co}$ (II) complexes and permeation through LEM, the following simple first order rate equations ( 6 and 7 ) was applied.

$\frac{C_{t}}{C_{0}}=e^{-k_{o b s} t}$

$\ln \frac{C_{t}}{C_{0}}=-k_{o b s} t$
Where $\left(\mathrm{C}_{t}\right)$ and $\left(\mathrm{C}_{0}\right)$ are the concentration of $\mathrm{Co}_{\text {(II) }}$ remained at time $(\mathrm{t})$ and the initially present in the outer phase solutions, respectively Figure $\mathbf{8}$. Represents the first order plots for different parameters affecting on cobalt permeation and the values of $k_{o b s}$ were calculated from the slopes of straight lines. The plot of log-log relations between $k_{o b s}$ and these different parameters gave linear relations. Plotting log $K$ obs versus logarithm of the $\left[\mathrm{H}^{+}\right]$, [CYANEX 301], [Co (II)] and $[\mathrm{HCl}]$ concentrations, gives their power dependency Figure 9. From this figure, it is clear that the rate constant was inversely dependent on $\left[\mathrm{HNO}_{3}\right]$ concentration in external phase and on [Co (II)] concentrations where slopes $\approx-1$ and -1.5 , respectively were obtained. But the rate constant depends on [CYANEX 301] concentration as extractant as a slope $\approx 1$ was obtained. The rate constant was found to be independent on $[\mathrm{HCl}]$ concentration in the internal phase. From these data, the rate of Co (II) permeation at $25{ }^{\circ} \mathrm{C}$ at a ratio of membrane to external phase volume of 0.1 can be represented by the following relation:

$\mathrm{d}[\mathrm{C}]_{\text {per }} / \mathrm{d}_{\mathrm{t}}=\mathrm{K}\left[\mathrm{HNO}_{3}\right]^{-1} \quad\left[\begin{array}{ll}\mathrm{Co} & (\mathrm{II})]^{-1.5}\end{array} \text { [CYANEX }^{301}\right]^{1}$ $[\mathrm{HCl}]^{0.12}$

Where $[\mathrm{C}]_{\text {per }}$ is the concentration of the permeated $\mathrm{Co}(\mathrm{II})$ and $\mathrm{K}$ is a constant.

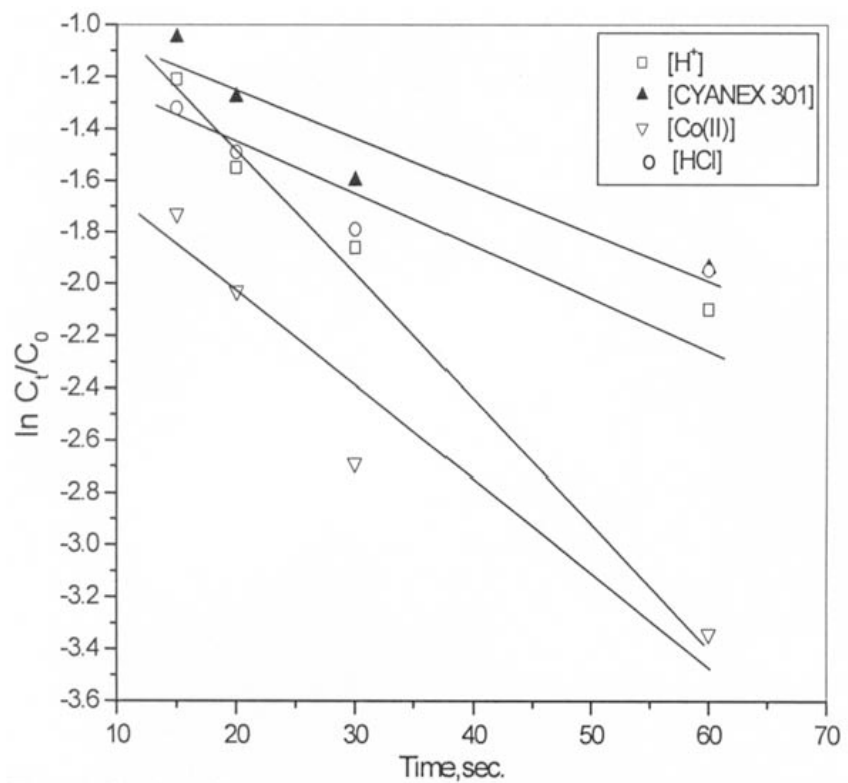

Figure 8: First order plot for the permeation of Cobalt through LEM.

\section{CONCLUSIONS}

In conclusion, the present study has shown that Co (II) can be effectively extracted by CYANEX 301 at low 


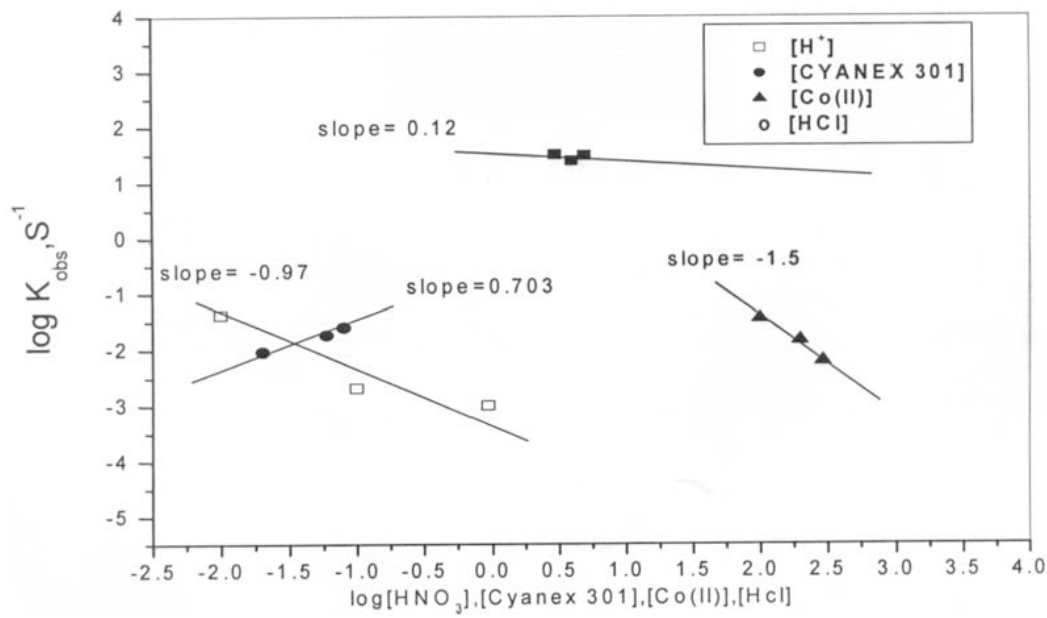

Figure 9: Effect og [HNO3], [Cyanex], [Co(II)] and [HCl] concentrations on the rate constant of cobalt permeation.

nitric acid concentration $\left(10^{-2} \mathrm{M}\right)$. The results showed that cyclohexane gives the maximum extraction (88\%) as diluent and hydrochloric acid gave better stripping results. The optimum conditions for cobalt (II) extraction were found as follows, concentration of CYANEX 301 was $8 \%$, concentration of $\mathrm{HCl}$ was $3 \mathrm{M}$, concentration of surfactant (span 80 ) was $4 \%$. By using these optimum conditions, $10 \mathrm{ml}$ of liquid emulsion membrane can extract $1 \mathrm{gm} / \mathrm{l}$ of cobalt (II) from nitric acid solution with extraction percentage $96.86 \%$ as a maximum extraction percent after $5 \mathrm{~min}$.

\section{REFERENCES}

[1] Forsythe JHW, Magee RJ, Wilson CL. The analytical chemistry of the pyridine thiocyanates-I: The separation of cobalt and nickel by solvent extraction. Talanta 1958; (1): 249-51.

http://dx.doi.org/10.1016/0039-9140(58)80041-7

[2] Li NN. Separating hydrocarbons with liquid membranes US Patent 3,410,794, 1968

[3] Cahn RP, Li NN. New Development in Separation Methods. Marcel Dekker Inc., New York 1976; pp. 13-27.

[4] Park Y, Skell AHP, Forney LJ, Kim JH. Removal of Phenol and Substituted Phenols by Newly Developed Emulsion Liquid Membrane Process. Water Res 2006; (40): 1763-72. http://dx.doi.org/10.1016/j.watres.2006.03.005

[5] Luan J, Plaisicr A. Study on treatment of wastewater containing nitrophenol compounds by liquid membrane process. J Membr Sci 2004; (229): 235-39. http://dx.doi.org/10.1016/j.memsci.2003.08.019

[6] Chakraborty M, Bart HJ. Emulsion liquid membranes: Role of internal droplet size distribution on toluene/n-heptane separation. Colloids Surfaces A: Physicochemical and Engineering Aspects 2006; (272): 15-21. http://dx.doi.org/10.1016/j.colsurfa.2005.07.002

[7] Boyadzhiev L, Lazarova Z. Study on creeping film pertraction. Recovery of copper from diluted aqueous solutions. Chem Eng Sci 1987; 42(5): 1131-35. http://dx.doi.org/10.1016/0009-2509(87)80062-3

[8] Raghuraman B, Tirmizi N, Wiencek J. Extraction with emulsion liquid membranes in a hollow fiber contactor. AIChE J 1993; (39): 39-46.
[9] Raghuraman B, Tirmizi N, Wiencek J. Emulsion liquid membranes for wastewater treatment: equipment models for some typical metal-extraction systems. Environ Sci Technol 1994; (28): 1090-102. http://dx.doi.org/10.1021/es00055a018

[10] Kasaini H, Nakashio F, Goto M, Application of emulsion liquid membranes to recover cobalt ions from a dual-component sulphate solution containing nickel ions. J Membr Sci 1998; (146): 159-68. http://dx.doi.org/10.1016/S0376-7388(98)00105-7

[11] Uddin MS, Kathiresan M. Extraction of metal ions by emulsion liquid membrane using bi-functional surfactant: equilibrium and kinetic studies. Sepa Purif Tech 2000; (19): 3-9.

[12] Chakravarti AK, Chowdhury SB, Mukherjee DC. Liquid membrane multiple emulsion process of separation of copper (II) form waste waters. Colloids and Surfaces a: Physiochemical and Engineering Aspects 2000; 166(1): 7-25. http://dx.doi.org/10.1016/S0927-7757(99)00452-5

[13] Saravanan S, Begum KMMS, Anantharaman N. Removal of hexavalent chromium by emulsion liquid membrane technique. J Univ Chem Technol Metallur 2006; 41(3): 33342.

[14] Valenzuela F, Araneda C, Vargas F, Basualto C, Sapag J. Liquid membrane emulsion process for the recovery the copper content of a mine drainage 2009.

[15] Chemical Engineering Research and Design, 87(1): 102-108. http://dx.doi.org/10.1016/j.cherd.2008.05.010

[16] Bhuvaneswari S, Begum KMMS, Sivashanmugam $P$ Anantharaman N. Separation of L-Glutamic acid by liquid emulsion membrane extraction. J Scient Ind Res 2003; (62): 329-33.

[17] Venkatesan S, Begum KMMS, Sivashanmugam $P$ Anantharaman N. Extraction of L-Glutamic acid by liquid emulsion membrane. J Indian Chem Soc 2004; (81): 1-3.

[18] Li NN. Liquid membrane processes for copper extraction. Hydrometallurgy 1983; (9): 277-305. http://dx.doi.org/10.1016/0304-386X(83)90027-0

[19] Sahoo GC, Dutta NN. Studies on emulsion liquid membrane extraction of cephalexin. J Membr Sci 1998; (145): 15-26. http://dx.doi.org/10.1016/S0376-7388(98)00027-1

[20] Gurel L, Altas L, Buyukgungor H. Removal of Lead from Wastewater Using Emulsion Liquid Membrane Technique. Environ Eng Sci 2005; 22(4): 411-20.

http://dx.doi.org/10.1089/ees.2005.22.411

[21] Noviandri I. Thesis, Magister of Science, Bandung Institute of Technology, Indonesia 1992. 
[22] Kondo K, Matsumoto $M$, Separation and concentration of indium (III) by an emulsion liquid membrane containing diisostearylphosphoric acid as a mobile carrier. Separ Purif Tech 1998; (13): 109-15.

http://dx.doi.org/10.1016/S1383-5866(97)00064-6

[23] Ye ZF, Wang YP, Liu YS, Jiang ZI, Shen X, Zhu IG, Shi XF. Transport of $\mathrm{Na}+, \mathrm{K}_{+}$ions in a bubbling pseudo-emulsion liquid membrane system with p-tert-butylcalixarenes as carrier. J Membr Sci 1999; (163): 367-72.

http://dx.doi.org/10.1016/S0376-7388(99)00180-5

[24] Park WG, Kim SS, Sohn I. Facilitated transport of $\mathrm{Cr}$ (VI) through a supported liquid membrane with trioctylmethylammonium chloride as a carrier. J Sep Sci Technol 2001; 36(10): 2309-26. http://dx.doi.org/10.1081/SS-100105920

[25] Kozlowski CW, Apostoluk W, Walkowiak, Kita A. Removal of $\mathrm{Cr}$ (VI), Zn (II) and Cd (II) ions by transport across polymer inclusion membranes with basic ion carriers. Physiochem Probl Mineral Proc 2002; (36): 115-22.

[26] Bourenane ME, Samar H, Abbaci A. Extraction of cobalt and lead from waste water using a liquid surfactant membrane emulsion. Acta Chim Slov 2003; (50): 663-75.

[27] Basualto C, Poblete M, Marchese J, Ochoa A, Acosta A, Sapag J, Valenzuela F. Extraction of Cadmium from Aqueous Solutions by Emulsion Liquid Membranes using a Stirred Transfer Cell Contactor. J Braz Chem Soc 2006; 17(7): 1347-54.

http://dx.doi.org/10.1590/S0103-50532006000700023

[28] Sabry R, Hafez A, Khedr M, Hassanin AE. Removal of lead by an emulsion liquid membrane: Part I. Desalination 2007; 212(1-3): 165-75. http://dx.doi.org/10.1016/j.desal.2006.11.006

[29] Yang L, Zhang Z, Guo Y, Gao X, Takeuchi H. Uranium (VI) extraction by liquid surfactant membrane with $\mathrm{N}$ alkylcaprolactams as a carrier. Separ Purif Tech 2005; (47): 88-94.

http://dx.doi.org/10.1016/j.seppur.2005.06.007

[30] Kozlowski C, Walkowiak W. Applicability of liquid membranes in chromium (VI) transport with amines as ion carriers. $J$ Membr Sci 2005; 266(1-2): 143-50.

http://dx.doi.org/10.1016/j.memsci.2005.04.053
[31] Farhadi K, Shamsipur M, Separation Study of Cadmium as Cdl42- through a Bulk Liquid Membrane Containing Ketoconazole and Oleic Acid. Anal Sci 2005; (21): 501-505. http://dx.doi.org/10.2116/analsci.21.501

[32] Gawronski R, Religa P. Transport mechanism of chromium (III) through the unmixed bulk liquid membrane containing dinonylnaphthalenesulfonic acid as a carrier. J Membr Sci 2007; 289(1-2): 187-90. http://dx.doi.org/10.1016/j.memsci.2006.11.053

[33] Chiha M, Samar MH, Hamdaoui O. Extraction of chromium (VI) from sulphuric acid aqueous solutions by a liquid surfactant membrane (LSM). Desalination 2006; (194): 6980.

http://dx.doi.org/10.1016/..desal.2005.10.025

[34] Ribeiro CP, Costa AOS, Lopes IPB, Campos FF, Ferreira AA, Salum A. Cobalt extraction and cobalt-nickel separation from simulated industrial leaching liquor by liquid surfactant membranes using Cyanex 302 as carrier. Membr Sci 2004; (241): 45-54.

[35] Thakul NV, Mishra SL. Separation of Cobalt, Nickel, and Copper by Solvent Extraction using di-(2-ethylhexyl) Phosphoric Acid, PC88A. Hydrometallurgy 1998; (48): 277.

[36] Longquan L, Cheng W, Yadong L, Separation of Cobalt and Nickel by Emulsion Liquid Membrane with the Use of EDTA as Masking Reagent. J Membr Sci 1997; (135): 173.

[37] Reddy BR, Radhika P, Kumar JR, Priya DN, Rajgopal K. Extractive spectrometric determination of $\mathrm{Co}$ (II) in synthetic and pharmaceutical samples using CYANEX 923. Anal Sci 2004; (20): 345-49. http://dx.doi.org/10.2116/analsci.20.345

[38] Gupta B, Tandon SN, Deep A, Recovery of cobalt and nickel from spent catalysts using CYANEX 923, in: Proceedings of the International Solvent Extraction Conference, ISEC 2002; pp. 793-797.

[39] Teramoto $M$, Sakaramoto $T$, Koyama $T$, Matsuyama $H$, Miyake Y. Extraction of lanthanoids by liquid surfactant memrannes. Sep Sci Technol 1986; 21(3): 229-50. http://dx.doi.org/10.1080/01496398608058375

\section{DOI: http://dx.doi.org/10.6000/1929-6037.2013.02.01.10}

(C) 2013 Mohamed et al.; Licensee Lifescience Global.

This is an open access article licensed under the terms of the Creative Commons Attribution Non-Commercial License (http://creativecommons.org/licenses/by-nc/3.0/) which permits unrestricted, non-commercial use, distribution and reproduction in any medium, provided the work is properly cited. 